\title{
A Study on the Relationship among Obesity, Suicide Plans, and Suicide Attempts: The 2018 Korea National Health and Nutrition Examination Survey
}

\author{
Jung Hyuck Park, MD', Mi Kyoung Seo, PhD², Taekjoong Kim, MD, PhD³, Sung Woo Park, PhD ${ }^{2,4,5}$, \\ Jung Goo Lee, MD, PhD ${ }^{1,2,5}$ \\ ${ }^{1}$ Department of Psychiatry, Haeundae Paik Hospital, College of Medicine, Inje University, ${ }^{2}$ Paik Institute for Clinical Research, Inje \\ University, ${ }^{3}$ Department of Humanities and Social Sciences in Medicine, College of Medicine, Inje University, ${ }^{4}$ Department of Convergence \\ Biomedical Science, College of Medicine, Inje University, ${ }^{5}$ Department of Health Science and Technology, Graduate School, Inje University, \\ Busan, Korea
}

Background: This study explores the correlation among obesity, suicide plans, and suicide attempts in adults over 19 years of age in South Korea.

Methods: The study used data from adults who had participated in the 2018 Korea National Health and Nutrition Examination Survey. Obesity was defined as having a body mass index of $\geq 25 \mathrm{~kg} / \mathrm{m}^{2}$. To identify differences between the characteristics of those who had reported suicide plans and attempts, a complex sample chi-square test was conducted. To analyze the effect of obesity on suicide plans and attempts, a logistic regression analysis was performed. Results: There was no significant difference in the rate of suicide plans in one year between obese and non-obese groups; however, the rate of actual suicide attempts was significantly high in the obese group $(p<0.050)$. After correcting for variables that were significantly different between the groups, obesity was found to have no significant effect on suicide plans but was linked to a significant increase in suicide attempts (odds ratio=3.355, $p=0.008$ ).

Conclusion: Obesity was found to have no effect on the suicide planning rate; however, the probability of a suicide attempt was high in obese adults.

Keywords KNHANES; Obesity; Suicide; Suicidal attempt

\section{INTRODUCTION}

Obesity is defined as the state of having accumulated excess levels of fat in the body. As there are no methods to accurately measure and evaluate the amount of fat in the body, the body mass index (BMI) is used as an indirect evaluation method. BMI is defined as a person's weight $(\mathrm{kg})$ divided by the square of their height $\left(\mathrm{m}^{2}\right)$. According to the criteria set by the World Health Orga- nization, BMI can be divided into five categories: underweight (BMI $<18.5 \mathrm{~kg} / \mathrm{m}^{2}$ ), normal weight (BMI 18.5 $24.9 \mathrm{~kg} / \mathrm{m}^{2}$ ), overweight (BMI $25-29.9 \mathrm{~kg} / \mathrm{m}^{2}$ ), obesity stage one (BMI $30-34.9 \mathrm{~kg} / \mathrm{m}^{2}$ ), obesity stage two (BMI $\left.35-39.9 \mathrm{~kg} / \mathrm{m}^{2}\right)$, and obesity stage three (BMI $\geq 40.0 \mathrm{~kg} /$ $\mathrm{m}^{2}$ ). As the prevalence of obesity-related diseases doubles at a BMI of $25 \mathrm{~kg} / \mathrm{m}^{2}$ in South Korea, different standards from those in Western countries are used to divide BMI into five stages: underweight (BMI $<18.5 \mathrm{~kg} / \mathrm{m}^{2}$ ),

Received January 22, 2021, Revised February 23, 2021, Accepted February 24, 2021

Correspondence: Sung Woo Park, PhD

Paik Institute for Clinical Research, Inje University, 75 Bokji-ro, Busanjin-gu, Busan 47392, Korea

TEL +82-51-890-6749 FAX +82-51-894-6709 E-mail swpark@inje.ac.kr ORCID https://orcid.org/0000-0001-8601-9084

Co-Correspondence: Jung Goo Lee, MD, PhD

Paik Institute for Clinical Research, Inje University, 75 Bokji-ro, Busanjin-gu, Busan 47392, Korea

TEL +82-51-890-6749 FAX +82-51-894-6709 E-mail iybihwc@inje.ac.kr ORCID https://orcid.org/0000-0003-3393-2667

Copyright () by Korean Society for Affective Disorders. All Rights reserved.

This is an Open Access article distributed under the terms of the Creative Commons Attribution Non-Commercial License (http://creativecommons.org/licenses/ by-nc/4.0/) which permits unrestricted non-commercial use, distribution, and reproduction in any medium, provided the original work is properly cited. 
normal weight (BMI 18.5-23 kg/m²), overweight (BMI 23-24.9 kg/m²), obesity stage one (BMI $25-29.9 \mathrm{~kg} / \mathrm{m}^{2}$ ), obesity stage 2 (BMI $30-34.9 \mathrm{~kg} / \mathrm{m}^{2}$ ), and obesity stage 3 $\left(\mathrm{BMI} \geq 35.0 \mathrm{~kg} / \mathrm{m}^{2}\right)$ [1].

The prevalence of obesity and overweight has doubled since 1980 worldwide, and approximately a third of the world's population are currently classified as overweight or obese [2]. Due to the westernization of diets in South Korea, the prevalence of obesity has gradually increased from $29.7 \%$ in 2009 to $32.4 \%$ in 2015 [3]. Obesity is also associated with physical ailments such as high blood pressure, dyslipidemia, diabetes, coronary artery disease, and stroke [4]; furthermore, there is evidence of relationships between obesity and mental illness [5], but the mechanisms remain unclear.

Suicide is defined as the act of an individual intentionally ending their own life. It is a significant issue around the world and affects society at the public health, community, individual, and familial levels. Well-known risk factors for suicide include demographic factors such as individual vulnerability due to medical mental health disorders and substance abuse, low social support system, marital status, employment status, stress, and sex [6-9]. Potential risk factors include biological indicators such as blood cholesterol levels and anthropometric measurements such as body weight; however, the correlation between suicide and obesity remains unclear [10].

Several previous studies have shown a positive relationship between obesity and suicide [11-14]; however, other studies have shown an inverse association [15-17].

Both obesity and suicide are public health issues that have recently attracted interests, and it is important to clarify the relationship between the two to establish health policies for suicide prevention.

This study intended to explore the correlation between obesity and suicide plans and attempts in adults over the age of 19 in South Korea using the 2018 Korea National Health and Nutrition Examination Survey results.

\section{MATERIALS AND METHODS}

\section{Method}

This study was conducted using data from the 2018 Korea National Health and Nutrition Examination Survey. The Korea National Health and Nutrition Examination Survey is a statutory survey on health behaviors, prevalence of chronic diseases, and food and nutrition intake conducted in accordance with the National Health Promotion Act. Each survey from the first (1998) to the third (2005) was conducted every three years; subsequently, it was reorganized into a year-round survey system and has been conducted every year from the fourth survey (2007-2009) to present. This study used the original data from the 7th Korea National Health and Nutrition Examination Survey of the third year conducted in 2018.

The Korea National Health and Nutrition Examination Surveys are conducted with the approval of the Research Ethics Review Committee of the Korea Centers for Disease Control and Prevention, and the results of the survey are announced through the distribution of press releases, publication of statistics, and disclosure of raw data from December of the following year. The Korea Centers for Disease Control and Prevention only provides de-identified data to ensure individuals cannot be identified. When weights were used in the process of analyzing data from Korea National Health and Nutrition Examination Surveys, inclusion errors due to differences in the number of households and population between the time of sample design and survey, unequal sampling ratio, and non-response error from non-participants were corrected to improve the representativeness and accuracy of estimates related to health behaviors, prevalence of chronic diseases, and food and nutritional intake of the people of South Korea.

In 2018, 10,453 people were surveyed, of whom 7,992 were engaged as participants of this study, and the participation rate was $76.5 \%$. The original data consisted of a health survey, examination survey, and nutrition survey, and this study utilized the results of the health survey and examination survey. The health survey included interviews and self-reporting surveys, and the examination included physical measurements, blood pressure and pulse measurements, and blood and urine test results. This study was conducted after obtaining approval from the Inje University Haeundae Paik Hospital Institutional Review Board (IRB NO. 2020-04-006). This study was exempted from obtaining written informed consent.

\section{Participants}

From a total of 7,992 samples, 6,489 participants were extracted, excluding 1,503 participants under the age of 19. After further excluding 1,408 participants with miss- 
ing values regarding the main variable, 5,081 participants were included as subjects in this study (Fig. 1).

\section{Research variables}

This study aimed to verify the effect of obesity on suicide plans and attempts. Therefore, obesity, suicide plans in the one year, and suicide attempts in the one year were used as variables, and general characteristics and health-related characteristics were used included as confounding variables. Suicide plans in one year and suicide attempts in one year, which were the dependent variables, were classified as 'yes' or 'no' depending on whether they were reported by study subjects. Obesity, an independent variable, was classified as ' $\mathrm{BMI} \geq 25$ ' or 'BMI <25.' As the number of subjects who reported suicide plans or attempts was minimal, there were many groups in which there were fewer than five subjects with suicide plans or attempts in cross-analysis when the results were subdivided to include underweight participants. Therefore, subjects were classified as 'BMI $\geq 25$ ' or 'BMI <25.' In terms of age, subjects were divided into groups of 19-29 years of age, 30-39 years of age, 40-49 years of age, 50-59 years of age, 60-69 years of age, and $\geq 70$ years of age, and sex was divided into male and female. Educational background was classified as high school graduate or lower and university graduate or higher, and marital status was divided into married and unmarried. Employment status was classified as employed and unemployed, and the household income was classified as low if it was in the first or second quartile and high group if it was in the third or fourth quartile of incomes. Alcohol consumption was divided into drinkers and non-drinkers according to whether

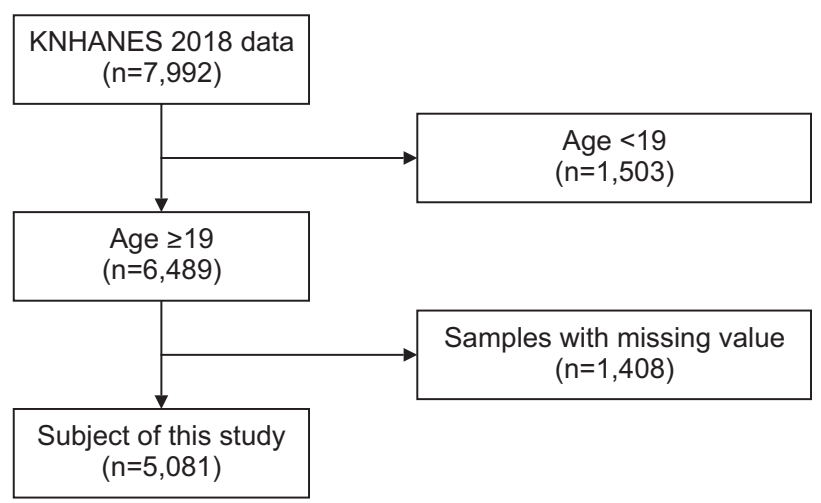

Fig. 1. Flowchart of study subject selection. KNHANES, Korea National Health and Nutrition Examination Survey. participants drank more than once a month, and smoking was divided into smokers and non-smokers according to whether they had smoked more than five packs in their lifetime. Physical activity was categorized into 'yes' or 'no' groups based on strength training. Presence of hypertension, diabetes, dyslipidemia, stroke, myocardial infarction and angina, thyroid disease, cancer, depression, renal failure, and cirrhosis were classified as yes or no according to the diagnosis from a doctor. Major health-related variables were also included as correction variables. Systolic blood pressure, diastolic blood pressure, fasting blood glucose, glycated hemoglobin, triglycerides, high-density lipoprotein (HDL) cholesterol, high-sensitivity C-reactive protein (hsCRP), and the total score of the Patient Health Questionnaire-9 (PHQ9), a depressive screening tool, were used in this study.

\section{Analysis method}

As the Korea National Health and Nutrition Examination Survey was performed using a two-stage stratified random sampling design and not a simple random sample design, the contents of the complex sampling should be reflected when the analyzing data. Therefore, in this study, a complex sample analysis was conducted by reflecting the weight, enumeration district, and variance estimation. The summary of the complex sample analysis method conducted for this study is as follows.

First, a complex sample $\chi^{2}$ test was conducted to identify the general and health-related characteristics of participants according to obesity, and to verify the difference between suicide plans and attempts according to the general characteristics and health-related characteristics of participants.

Second, analysis of variance was conducted using a general linear model to verify the difference in healthrelated variables according to obesity status, suicide plans, and suicide attempts.

Third, a logistic regression analysis was performed to confirm the effect of obesity on suicide plans and attempts, and to verify the factors influencing suicide plans and attempts.

The IBM SPSS Statistics for Windows, Version 25.0 (IBM Co., Armonk, NY, USA) was used for statistical analyses, and statistical significance was determined based on the significance level of 0.050 . 
Jung Hyuck Park, et al. Obesity and Suicide

Table 1. Comparison of general characteristics and health-related characteristics between obese and non-obese participants

\begin{tabular}{|c|c|c|c|c|c|}
\hline Variable & Obese $(n=1,874)$ & Non-obese $(n=3,207)$ & Total $(n=5,081)$ & $\chi^{2}$ & $\mathrm{p}$-value \\
\hline \multicolumn{6}{|c|}{ General characterstics } \\
\hline \multicolumn{6}{|l|}{ Age (y) } \\
\hline $19-29$ & $159(8.5)$ & $394(12.3)$ & $553(10.9)$ & 17.177 & 0.042 \\
\hline $30-39$ & $291(15.5)$ & $465(14.5)$ & $756(14.9)$ & & \\
\hline $40-49$ & $361(19.3)$ & $597(18.6)$ & $958(18.9)$ & & \\
\hline $50-59$ & $357(19.1)$ & $655(20.4)$ & 1,012 (19.9) & & \\
\hline $60-69$ & $366(19.5)$ & $569(17.8)$ & $935(18.4)$ & & \\
\hline$\geq 70$ & $340(18.1)$ & $527(16.4)$ & $867(17.0)$ & & \\
\hline \multicolumn{6}{|l|}{ Sex } \\
\hline Male & $996(53.1)$ & $1,303(40.6)$ & 2,299 (45.2) & 102.064 & $<0.001$ \\
\hline Female & $878(46.9)$ & $1,904(59.4)$ & $2,782(54.8)$ & & \\
\hline \multicolumn{6}{|l|}{ Education } \\
\hline$\geq$ College & $668(35.6)$ & $1,248(38.9)$ & 1,916 (37.7) & 0.199 & 0.666 \\
\hline$\leq$ High school & $1,206(64.4)$ & $1,959(61.1)$ & $3,165(62.3)$ & & \\
\hline \multicolumn{6}{|l|}{ Marriage } \\
\hline Married & $1,609(85.9)$ & $2,647(82.5)$ & $4,256(83.8)$ & 8.933 & 0.041 \\
\hline Single & $265(14.1)$ & $560(17.5)$ & $825(16.2)$ & & \\
\hline \multicolumn{6}{|l|}{ Occupation } \\
\hline Yes & $1,219(65.0)$ & $2,017(63.0)$ & $3,236(63.7)$ & 4.217 & 0.090 \\
\hline No & $655(35.0)$ & $1,190(37.0)$ & $1,845(36.3)$ & & \\
\hline \multicolumn{6}{|l|}{ Household income } \\
\hline High & $1,044(55.7)$ & $1,895(59.1)$ & 2,939 (57.8) & 0.644 & 0.546 \\
\hline Low & $830(44.3)$ & $1,312(40.9)$ & $2,142(42.1)$ & & \\
\hline \multicolumn{6}{|c|}{ Health-realted characterstics } \\
\hline \multicolumn{6}{|l|}{ Drinking } \\
\hline Yes & $1,069(57.0)$ & $1,708(53.3)$ & $2,777(54.7)$ & 7.719 & 0.022 \\
\hline No & $805(43.0)$ & $1,499(46.7)$ & 2,304 (45.3) & & \\
\hline \multicolumn{6}{|l|}{ Smoking } \\
\hline Yes & $820(43.8)$ & $1,176(36.7)$ & 1,996 (39.3) & 34.541 & $<0.001$ \\
\hline No & $1,054(56.2)$ & $2,031(63.3)$ & $3,085(60.7)$ & & \\
\hline \multicolumn{6}{|l|}{ Exercise } \\
\hline Yes & $422(22.5)$ & $807(25.2)$ & $1,229(24.2)$ & 3.896 & 0.131 \\
\hline No & $1,452(77.5)$ & $2,400(74.8)$ & $3,852(75.8)$ & & \\
\hline \multicolumn{6}{|l|}{ Hypertension } \\
\hline Yes & $646(34.5)$ & $633(19.7)$ & $1,279(25.2)$ & 105.301 & $<0.001$ \\
\hline No & $1,228(65.5)$ & $2,574(80.3)$ & $3,802(74.8)$ & & \\
\hline \multicolumn{6}{|l|}{ Diabetes mellitus } \\
\hline Yes & $229(12.2)$ & $243(7.6)$ & $472(9.3)$ & 17.043 & $<0.001$ \\
\hline No & $1,645(87.8)$ & $2,964(92.4)$ & $4,609(90.7)$ & & \\
\hline \multicolumn{6}{|l|}{ Dyslipidemia } \\
\hline Yes & $476(25.4)$ & $525(16.4)$ & $1,001(19.7)$ & 49.239 & $<0.001$ \\
\hline No & $1,398(74.6)$ & $2,682(83.6)$ & $4,080(80.3)$ & & \\
\hline \multicolumn{6}{|l|}{ Stroke } \\
\hline Yes & $53(2.8)$ & $64(2.0)$ & $117(2.3)$ & 2.444 & 0.106 \\
\hline No & $1,821(97.2)$ & $3,143(98.0)$ & 4,964 (97.7) & & \\
\hline \multicolumn{6}{|c|}{ Cardiovascular disease } \\
\hline Yes & $70(3.7)$ & $75(2.3)$ & $145(2.9)$ & 3.437 & 0.063 \\
\hline No & $1,804(96.3)$ & $3,132(97.7)$ & $4,936(97.1)$ & & \\
\hline
\end{tabular}


Table 1. Continued

\begin{tabular}{|c|c|c|c|c|c|}
\hline Variable & Obese $(n=1,874)$ & Non-obese $(n=3,207)$ & Total $(n=5,081)$ & $\chi^{2}$ & $p$-value \\
\hline \multicolumn{6}{|l|}{ Thyroid disease } \\
\hline Yes & $64(3.4)$ & $131(4.1)$ & 195 (3.8) & 1.119 & 0.385 \\
\hline No & $1,810(96.6)$ & $3,076(95.9)$ & $4,886(96.2)$ & & \\
\hline \multicolumn{6}{|l|}{ Depressive disorder } \\
\hline Yes & $78(4.2)$ & $157(4.9)$ & $235(4.6)$ & 3.585 & 0.056 \\
\hline No & $1,796(95.8)$ & $3,050(95.1)$ & $4,846(95.4)$ & & \\
\hline \multicolumn{6}{|l|}{ Renal failure } \\
\hline Yes & $3(0.2)$ & $8(0.2)$ & $11(0.2)$ & 0.517 & 0.371 \\
\hline No & $1,871(99.8)$ & 3,199 (99.8) & $5,070(99.8)$ & & \\
\hline \multicolumn{6}{|l|}{ Liver cirrhosis } \\
\hline Yes & $5(0.3)$ & $17(0.5)$ & $22(0.4)$ & 0.391 & 0.493 \\
\hline No & 1,869 (99.7) & $3,190(99.5)$ & $5,059(99.6)$ & & \\
\hline
\end{tabular}

Values are presented as number (\%).

Table 2. Comparison of health-related variables between obese and non-obese participants

\begin{tabular}{lrrrrr}
\hline \multicolumn{1}{c}{ Variable } & Obese $(n=1,874)$ & Non-obese $(n=3,207)$ & Total $(n=5,081)$ & $F$ & $p$-value \\
\hline Systolic blood pressure & $122.15 \pm 0.50$ & $115.44 \pm 0.40$ & $117.95 \pm 0.37$ & 168.154 & $<0.001$ \\
Diastolic blood pressure & $79.37 \pm 0.31$ & $74.64 \pm 0.24$ & $76.41 \pm 0.22$ & 177.299 & $<0.001$ \\
Blood glucose & $105.42 \pm 0.65$ & $98.05 \pm 0.45$ & $100.81 \pm 0.40$ & 99.396 & $<0.001$ \\
HbA1c & $5.82 \pm 0.02$ & $5.60 \pm 0.02$ & $5.68 \pm 0.02$ & 65.035 & $<0.001$ \\
Triglyceride & $171.28 \pm 4.29$ & $120.99 \pm 2.19$ & $139.83 \pm 2.12$ & 106.717 & $<0.001$ \\
HDL cholesterol & $46.53 \pm 0.30$ & $52.96 \pm 0.34$ & $50.55 \pm 0.27$ & 257.083 & $<0.001$ \\
hSCRP & $1.45 \pm 0.05$ & $0.91 \pm 0.03$ & $1.11 \pm 0.03$ & 73.734 & $<0.001$ \\
PHQ-9 score & $2.25 \pm 0.11$ & $2.32 \pm 0.07$ & $2.29 \pm 0.07$ & 0.328 & 0.567 \\
\hline
\end{tabular}

Values are presented as mean \pm standard deviation.

$\mathrm{HbA1C}$, hemoglobin A1c; HDL, high-density lipoprotein; hsCRP, high sensitivity C-reactive protein; PHQ-9, Patient Health Questionnaire-9.

\section{RESULTS}

\section{Characteristics of the participants in relation to obesity}

A complex sample $\chi^{2}$ test was conducted to identify the general characteristics and health-related characteristics of the study subjects and confirm the relationship between general characteristics, helath-related characteristics and obesity (Table 1). There were significant differences in age, sex, and marital status between the obese and non-obese groups $(\mathrm{p}<0.050)$. The proportion of obese individuals was relatively low for those in their twenties and relatively high for those in their thirties. A greater proportion of men were obese than women, and more individuals who were married were obese than those who were unmarried. There were significant differences in the prevalence of alcohol, smoking, hypertension, diabetes, and dyslipidemia in relation to obesity $(p<0.050)$. The alcohol consumption rate and smoking rate was also higher in the obese group. The prevalence of hypertension, diabetes, and dyslipidemia was higher in the obese group. An analysis of variance was conducted on the complex sample using a general linear model to identify health-related variables that were significantly different according to obesity status (Table 2). As a result, all health-related variables showed significant differences in relation to obesity $(\mathrm{p}<0.010)$ except for total PHQ-9 score. Blood pressure, fasting blood glucose, glycated hemoglobin, triglyceride, and hsCRP were all higher in the obese group, and HDL cholesterol was lower in the obese group. 


\section{Suicide plans and attempts in one year in relation to obesity}

A $\chi^{2}$ test was conducted to verify the difference between suicide plans and attempts in one year in relation to obesity (Table 3). As a result, there was no significant difference in suicide plans throughout one year in relation to obesity, but there was a significant difference in suicide attempts throughout one year in relation to obesity $(\mathrm{p}<0.050)$. The suicide attempt rate was $0.5 \%$ in the non-obese group and $0.9 \%$ in the obese group, which was significantly higher.

\section{Suicide plans and attempts in one year in relation to the characteristics of participants}

The $\chi^{2}$ test was conducted to verify the difference between suicide plans and attempts in one year according to the general characteristics and health-related characteristics of the study subjects (Table 4). As a result, the rate of suicide plans in one year showed significant differences according to education level, employment status, and household income, and rate of suicide attempts in one year showed significant differences according to sex and employment status $(\mathrm{p}<0.050)$. The suicide planning rate was relatively higher for those with an education level of high school graduates or lower than for those with a college degree or higher, and the rate was also higher for the unemployed and those with low household incomes. The suicide attempt rate was higher for women than men, and higher in the unemployed. Suicide plans in one year was significantly different according to the presence of stroke, heart disease, depression, and cirrhosis, and suicide attempts in one year was significantly different according to the presence of diabetes, stroke, and depression $(\mathrm{p}<0.050)$. The suicide planning rate was higher in participants with stroke, heart disease, depression, and cirrhosis. The suicide attempt rate was lower in those with diabetes, and higher in participants with stroke and depression. An analysis of variance was conducted using the complex sample general linear model to verify whether health-related variables showed significant differences in relation to suicide plans and attempts (Table 5). The PHQ-9 score was significantly different between those with a suicide plan and those without; similarly, the PHQ-9 score was significantly different between those with a suicide attempt and those without $(\mathrm{p}<0.050)$. In the PHQ-9, there was a higher rate of presence of suicide plans and attempts than the absence of suicide plans or attempts.

\section{Effects of obesity on suicide plans and attempts in one year}

A Complex sample logistic regression analysis was conducted to verify the effect of obesity on suicide plans and suicide attempts in one year (Table 6). Variables that showed a significant difference with respect to suicide plans were entered as correction variables. As a result, obesity did not have a significant effect on suicide planning in one year; in terms of correction variables, it education level, depression prevalence, and PHQ-9 score had a significant effect on suicide planning. In terms of education level, those with a college degree or higher were less likely to plan suicide (odds ratio [OR], 0.313; $\mathrm{p}=0.017$ ), and participants with depression were more likely to plan suicide than those without depression (OR, 2.314; $\mathrm{p}=0.045$ ). The probability of suicide planning increased with a higher PHQ-9 score (OR, 1.222; $\mathrm{p}<0.001)$. Variables that previously showed significant differences with respect to suicide attempts in one year were entered as correction variables. As a result, obesity had a significant effect on suicide attempts; according to the correction variables, diabetes and PHQ-9 had a sig-

Table 3. Comparison of suicide plans and attempts between obese and non-obese participants

\begin{tabular}{|c|c|c|c|c|c|}
\hline Variable & Obese $(n=1,874)$ & Non-obese $(n=3,207)$ & Total $(n=5,081)$ & $\chi^{2}$ & $p$-value \\
\hline \multicolumn{6}{|c|}{ Suicide plan } \\
\hline Yes & $34(1.8)$ & $45(1.4)$ & $79(1.6)$ & 1.660 & 0.259 \\
\hline No & $1,840(98.2)$ & $3,162(98.6)$ & $5,002(98.4)$ & & \\
\hline \multicolumn{6}{|c|}{ Suicide attempt } \\
\hline Yes & $17(0.9)$ & $15(0.5)$ & $32(0.6)$ & 6.864 & 0.017 \\
\hline No & $1,857(99.1)$ & $3,192(99.5)$ & $5,049(99.4)$ & & \\
\hline
\end{tabular}

Values are presented as number (\%). 
Mood and Emotion Vol. 19, No. 1, March

Table 4. Comparison of suicide plans and attempts according to general characteristicsand health-related characteristics

\begin{tabular}{|c|c|c|c|c|c|c|}
\hline \multirow{2}{*}{ Variable } & \multicolumn{2}{|c|}{ Suicide plan } & \multirow{2}{*}{$\chi^{2}(p)$} & \multicolumn{2}{|c|}{ Suicide attempt } & \multirow{2}{*}{$\chi^{2}(p)$} \\
\hline & Yes & No & & Yes & No & \\
\hline \multicolumn{7}{|c|}{ General characteristics } \\
\hline \multicolumn{7}{|l|}{ Age (y) } \\
\hline $19-29$ & $6(1.1)$ & $547(98.9)$ & $9.322(0.137)$ & $3(0.5)$ & $550(99.5)$ & $1.321(0.880)$ \\
\hline $30-39$ & $5(0.7)$ & $751(99.3)$ & & $6(0.8)$ & $750(99.2)$ & \\
\hline $40-49$ & $11(1.0)$ & 947 (98.9) & & $6(0.6)$ & $952(99.4)$ & \\
\hline $50-59$ & $14(1.4)$ & $998(98.6)$ & & $8(0.8)$ & $1,004(99.2)$ & \\
\hline $60-69$ & $23(2.5)$ & $912(97.5)$ & & $5(0.5)$ & $930(99.5)$ & \\
\hline$\geq 70$ & $20(2.3)$ & $847(97.7)$ & & $4(0.5)$ & $863(99.5)$ & \\
\hline \multicolumn{7}{|l|}{ Sex } \\
\hline Male & $31(1.3)$ & $2,268(98.7)$ & $2.604(0.113)$ & $7(0.3)$ & 2,292 (99.7) & $5.327(0.027)$ \\
\hline Female & $48(1.7)$ & $2,734(98.3)$ & & $25(0.9)$ & $2,757(99.1)$ & \\
\hline \multicolumn{7}{|l|}{ Education } \\
\hline$\geq$ College & $7(0.4)$ & 1,909 (99.6) & $18.189(0.001)$ & $5(0.3)$ & 1,911 (99.7) & $3.245(0.078)$ \\
\hline$\leq$ High school & $72(2.3)$ & $3,093(97.7)$ & & $27(0.9)$ & $3,138(99.1)$ & \\
\hline \multicolumn{7}{|l|}{ Marriage } \\
\hline Married & $70(1.6)$ & $4,186(98.4)$ & $0.616(0.525)$ & $26(0.6)$ & $4,230(99.4)$ & $0.617(0.548)$ \\
\hline Single & $9(1.1)$ & $816(99.0)$ & & $6(0.7)$ & $819(99.3)$ & \\
\hline \multicolumn{7}{|l|}{ Occupation } \\
\hline Yes & $41(1.3)$ & $3,195(98.7)$ & $6.586(0.009)$ & $16(0.5)$ & $3,220(99.5)$ & $3.765(0.039)$ \\
\hline No & $38(2.1)$ & $1,807(97.9)$ & & $16(0.9)$ & $1,829(99.1)$ & \\
\hline \multicolumn{7}{|l|}{ Household income } \\
\hline High & $26(0.9)$ & $2,913(99.1)$ & $13.656(0.001)$ & $12(0.3)$ & 2,927 (99.7) & $2.319(0.133)$ \\
\hline Low & $53(2.5)$ & $2,089(97.5)$ & & $20(0.9)$ & $2,122(99.1)$ & \\
\hline \multicolumn{7}{|c|}{ Health-related characteristics } \\
\hline \multicolumn{7}{|l|}{ Drinking } \\
\hline Yes & $38(1.4)$ & $2,739(98.6)$ & $0.170(0.708)$ & $15(0.5)$ & $2,762(99.5)$ & $0.014(0.905)$ \\
\hline No & $41(1.8)$ & $2,263(98.2)$ & & $17(0.7)$ & $2,287(99.3)$ & \\
\hline \multicolumn{7}{|l|}{ Smoking } \\
\hline Yes & $39(2.0)$ & $1,957(98.0)$ & $3.914(0.060)$ & $14(0.7)$ & 1,982 (99.3) & $0.849(0.424)$ \\
\hline No & $40(1.3)$ & $3,045(98.7)$ & & $18(0.6)$ & $3,067(99.4)$ & \\
\hline \multicolumn{7}{|l|}{ Exercise } \\
\hline Yes & $17(1.4)$ & $1,212(98.6)$ & $0.005(0.947)$ & $6(0.5)$ & $1,223(99.5)$ & $0.055(0.829)$ \\
\hline No & $62(1.6)$ & $3,790(98.4)$ & & $26(0.7)$ & $3,826(99.3)$ & \\
\hline \multicolumn{7}{|l|}{ Hypertension } \\
\hline Yes & $33(2.6)$ & $1,246(97.4)$ & $2.770(0.070)$ & $9(0.7)$ & $1,270(99.3)$ & $0.204(0.552)$ \\
\hline No & $46(1.2)$ & $3,756(98.8)$ & & $23(0.6)$ & $3,779(99.4)$ & \\
\hline \multicolumn{7}{|l|}{ Diabetes mellitus } \\
\hline Yes & $13(2.8)$ & $459(97.2)$ & $1.629(0.150)$ & $2(0.4)$ & $470(99.6)$ & $1.335(0.003)$ \\
\hline No & $66(1.4)$ & $4,543(98.6)$ & & $30(0.7)$ & 4,579 (99.3) & \\
\hline \multicolumn{7}{|l|}{ Dyslipidemia } \\
\hline Yes & $22(2.2)$ & $979(97.8)$ & $0.944(0.298)$ & $6(0.6)$ & 995 (99.4) & $0.221(0.546)$ \\
\hline No & $57(1.4)$ & $4,023(98.6)$ & & $26(0.6)$ & 4,054 (99.4) & \\
\hline \multicolumn{7}{|l|}{ Stroke } \\
\hline Yes & $8(6.8)$ & $109(93.2)$ & $8.933(<0.001)$ & $4(3.4)$ & $113(96.6)$ & $7.245(0.001)$ \\
\hline No & $71(1.4)$ & 4,893 (98.6) & & $28(0.6)$ & 4,936 (99.4) & \\
\hline
\end{tabular}


Table 4. Continued

\begin{tabular}{|c|c|c|c|c|c|c|}
\hline \multirow{2}{*}{ Variable } & \multicolumn{2}{|c|}{ Suicide plan } & \multirow{2}{*}{$\chi^{2}(p)$} & \multicolumn{2}{|c|}{ Suicide attempt } & \multirow{2}{*}{$\chi^{2}(p)$} \\
\hline & Yes & No & & Yes & No & \\
\hline \multicolumn{7}{|c|}{ Cardiovascular disease } \\
\hline Yes & $7(4.8)$ & $138(95.2)$ & $3.926(0.030)$ & $3(2.0)$ & $142(98.0)$ & $1.811(0.124)$ \\
\hline No & $72(1.5)$ & $4,864(95.5)$ & & $29(0.6)$ & 4,907 (99.4) & \\
\hline \multicolumn{7}{|l|}{ Thyroid disease } \\
\hline Yes & $4(2.1)$ & $191(97.9)$ & $0.143(0.663)$ & $1(0.5)$ & $194(99.5)$ & $0.099(0.659)$ \\
\hline No & $75(1.5)$ & $4,811(98.5)$ & & $31(0.6)$ & 4,855 (99.4) & \\
\hline \multicolumn{7}{|l|}{ Depressive disorder } \\
\hline Yes & $20(8.5)$ & $215(91.5)$ & $63.263(<0.001)$ & $9(3.8)$ & $226(96.2)$ & $23.807(<0.001)$ \\
\hline No & $59(1.2)$ & $4,787(98.8)$ & & $23(0.5)$ & 4,823 (99.5) & \\
\hline \multicolumn{7}{|l|}{ Renal failure } \\
\hline Yes & $0(0.0)$ & $11(100.0)$ & $0.077(0.758)$ & $0(0.0)$ & $11(100.0)$ & $0.032(0.841)$ \\
\hline No & $79(1.6)$ & 4,991 (98.4) & & $32(0.3)$ & $5,038(99.4)$ & \\
\hline \multicolumn{7}{|l|}{ Liver cirrhosis } \\
\hline Yes & $1(4.5)$ & $21(95.5)$ & $24.867(<0.001)$ & $0(0.0)$ & $22(100.0)$ & $0.085(0.813)$ \\
\hline No & $78(1.5)$ & $4,981(98.5)$ & & $32(0.6)$ & $5,027(99.4)$ & \\
\hline
\end{tabular}

Values are presented as number (\%).

Table 5. Comparison of health-related variables according to the presence of suicide plans and attempts

\begin{tabular}{|c|c|c|c|c|c|c|}
\hline \multirow{2}{*}{ Variable } & \multicolumn{2}{|c|}{ Suicide plan } & \multirow{2}{*}{$F(p)$} & \multicolumn{2}{|c|}{ Suicide attempt } & \multirow{2}{*}{$F(p)$} \\
\hline & Yes & No & & Yes & No & \\
\hline Systolic blood pressure & $118.12 \pm 1.98$ & $117.95 \pm 0.37$ & $0.008(0.929)$ & $115.67 \pm 2.60$ & $117.96 \pm 0.37$ & $0.784(0.377)$ \\
\hline Diastolic blood pressure & $74.81 \pm 1.15$ & $76.43 \pm 0.22$ & $1.929(0.166)$ & $76.67 \pm 2.11$ & $76.41 \pm 0.22$ & $0.016(0.900)$ \\
\hline Blood glucose & $109.47 \pm 4.65$ & $100.72 \pm 0.41$ & $3.431(0.065)$ & $100.92 \pm 4.50$ & $100.81 \pm 0.41$ & $0.001(0.981)$ \\
\hline $\mathrm{HbA1c}$ & $5.94 \pm 0.16$ & $5.68 \pm 0.02$ & $2.794(0.096)$ & $5.69 \pm 0.10$ & $5.68 \pm 0.02$ & $0.009(0.926)$ \\
\hline Triglyceride & $143.23 \pm 13.48$ & $139.79 \pm 2.13$ & $0.063(0.801)$ & $141.05 \pm 18.35$ & $139.83 \pm 2.13$ & $0.004(0.947)$ \\
\hline HDL cholesterol & $50.99 \pm 1.69$ & $50.55 \pm 0.27$ & $0.068(0.794)$ & $54.47 \pm 3.03$ & $50.53 \pm 0.27$ & $1.665(0.198)$ \\
\hline hsCRP & $1.71 \pm 0.32$ & $1.11 \pm 0.03$ & $3.481(0.063)$ & $1.36 \pm 0.35$ & $1.11 \pm 0.03$ & $0.474(0.492)$ \\
\hline PHQ-9 score & $9.10 \pm 1.07$ & $2.22 \pm 0.07$ & $40.956(<0.001)$ & $9.59 \pm 1.56$ & $2.26 \pm 0.07$ & $22.081(<0.001)$ \\
\hline
\end{tabular}

Values are presented as mean \pm standard deviation.

HbA1c, hemoglobin A1c; HDL, high-density lipoprotein; hsCRP, high sensitivity C-reactive protein; PHQ-9, Patient Health Questionnaire-9.

nificant effect on suicide attempts. In the case of obesity, the probability of suicide attempt was estimated to be approximately 3.355 times higher $(\mathrm{OR}, 3.355 ; \mathrm{p}=0.008)$, but the probability of suicide attempt in diabetic patients was rather low (OR, 0.068; $\mathrm{p}=0.001$ ). In addition, higher PHQ-9 scores were related to a higher probability of suicide attempts (OR, 1.223; $\mathrm{p}<0.001)$.

\section{DISCUSSION}

This study investigated the relationship between obesity and suicide plans and attempts in the general adult population in South Korea using original data from the Korea National Health and Nutrition Examination Survey and corrected the results based on control variables in reference to the original data.

Obesity did not significantly affect suicide planning, but there was a significant difference in suicide attempts $(p<0.050)$. Even after corrections were made for demographic factors, hematologic factors, and underlying 
Table 6. Effect of factors on suicide plans and suicide attempts

\begin{tabular}{|c|c|c|c|}
\hline Variable & OR & $95 \% \mathrm{Cl}$ & $p$-value \\
\hline \multicolumn{4}{|l|}{ Suicide plan } \\
\hline \multicolumn{4}{|l|}{ Obesity } \\
\hline Yes & 1.560 & $0.853-2.854$ & 0.148 \\
\hline No & 1.000 & & \\
\hline \multicolumn{4}{|l|}{ Education } \\
\hline$\geq$ College & 0.313 & $0.121-0.813$ & 0.017 \\
\hline$\leq$ High school & 1.000 & & \\
\hline \multicolumn{4}{|l|}{ Occupation } \\
\hline Yes & 1.180 & $0.596-2.337$ & 0.634 \\
\hline No & 1.000 & & \\
\hline \multicolumn{4}{|c|}{ Household income } \\
\hline High & 0.652 & $0.357-1.191$ & 0.163 \\
\hline Low & 1.000 & & \\
\hline \multicolumn{4}{|l|}{ Stroke } \\
\hline Yes & 1.366 & $0.496-3.758$ & 0.545 \\
\hline No & 1.000 & & \\
\hline \multicolumn{4}{|c|}{ Cardiovascular disease } \\
\hline Yes & 2.014 & $0.659-6.152$ & 0.218 \\
\hline No & 1.000 & & \\
\hline \multicolumn{4}{|c|}{ Depressive disorder } \\
\hline Yes & 2.314 & $1.018-5.256$ & 0.045 \\
\hline No & 1.000 & & \\
\hline \multicolumn{4}{|l|}{ Liver cirrhosis } \\
\hline Yes & 8.299 & $0.524-131.460$ & 0.133 \\
\hline No & 1.000 & & \\
\hline PHQ-9 & 1.222 & $1.164-1.282 \mid$ & $<0.001$ \\
\hline \multicolumn{4}{|l|}{ Suicide attempt } \\
\hline \multicolumn{4}{|l|}{ Obesity } \\
\hline Yes & 3.355 & $1.377-8.174$ & 0.008 \\
\hline No & 1.000 & & \\
\hline \multicolumn{4}{|l|}{ Sex } \\
\hline Male & 0.517 & $0.205-1.306$ & 0.162 \\
\hline Female & 1.000 & & \\
\hline \multicolumn{4}{|l|}{ Occupation } \\
\hline Yes & 0.877 & $0.408-1.885$ & 0.736 \\
\hline No & 1.000 & & \\
\hline \multicolumn{4}{|l|}{ Diabetes melitus } \\
\hline Yes & 0.068 & $0.013-0.351$ & 0.001 \\
\hline No & 1.000 & & \\
\hline \multicolumn{4}{|l|}{ Stroke } \\
\hline Yes & 3.124 & $0.745-13.091$ & 0.119 \\
\hline No & 1.000 & & \\
\hline \multicolumn{4}{|c|}{ Depressive disorder } \\
\hline Yes & 1.620 & $0.515-5.097$ & 0.409 \\
\hline No & 1.000 & & \\
\hline PHQ-9 & 1.223 & $1.150-1.300$ & $<0.001$ \\
\hline
\end{tabular}

OR, odds ratio; $\mathrm{Cl}$, confidence interval; $\mathrm{PHQ}-9$, Patient Health Questionnaire-9. diseases, people with obesity were three times more likely to attempt suicide than people without obesity (OR, 3.355; $\mathrm{p}=0.008)$. Such results support the results from international studies that showed a positive link between obesity and suicide [11-14].

This study classified obesity based on a BMI of $25 \mathrm{~kg} / \mathrm{m}^{2}$, and those below a BMI of $25 \mathrm{~kg} / \mathrm{m}^{2}$ were classified as controls, with underweight individuals not separately classified. Therefore, since underweight individuals were included in the control category, it is difficult to interpret that people who are simply obese are more likely to commit suicide.

According to recent studies, the possibility that there is a U-shaped association between BMI and psychological distress has been continuously raised, and such association has been confirmed in previous studies in Korea [18]. On the contrary, a representative study in Germany found that obese people had higher levels of depression and anxiety than overweight and normal weight, U-shaped model between the BMI-classes, depression, anxiety couldn't be confirmed [19]. In a situation where the possibility of such a U-shaped association is raised, the limitation of this study is that the category of underweight is not specified separately, but the strength of this study is that it shows that there is a strong association between obesity and suicide.

According to the results of a study conducted in South Korea, rates of suicide attempt were significantly higher in those who were underweight, and there was a tendency for the suicide rate to increase for people with obesity, but it was not statistically significant. Such results are quite contradictory to the results of this study [20]. In another cross-sectional study using the Korea National Health and Nutrition Examination Survey, the obese population was classified and analyzed by sex and age. There were many suicide attempts in severely obese women but the suicide attempts were higher for men when underweight, suggesting the possibility of a variable relationship between obesity and suicide according to sex and age [21]. However, as the number of studies on the relationship between obesity and suicide targeting Koreans are scarce, there are expected limitations in investigating clear correlations to clarify which results to generalize and apply. In addition, there are contradicting findings that both underweight and overweight may be associated with suicide. Therefore, it can be interpreted that deviating from the healthy weight range may be an important risk factor for suicide. Both 
personal and social factors can affect the psychological pain that people with obesity experience. Personal factors may include dissatisfaction with body shape and decreased self-esteem, and social factors may include social stigma due to stereotypes about obesity in Korean society. These factors lead to repeated binge eating and vomiting, and aberrant weight control behaviors, such as laxative abuse. Some recent research suggests that such behaviors indicate increased risk of suicide [22].

As this study used data from the Korea National Health and Nutrition Examination Survey conducted on adults in South Korea, it had the strength of having a large sample of reliable data representing the entire Korean group, accompanied by analysis of several demographic and sociological variables. In terms of limitations, first, there were limitations in identifying a temporal cause-and-effect relationship as this was a retrospective cross-sectional study with BMI calculated by measuring weight and height at the time of investigation; suicide plans and attempts were investigated using the method of responding yes or no to the question of having suicide plans or attempts in the past year at the time of the investigation. Second, sex analysis was not conducted separately between men and women, and sex was treated as a confounding variable to reduce its effect on the outcome. Third, as the data used in this study were not surveys designed for professional mental health evaluation, there were limitations in terms of survey items. For example, the presence of depression was identified according to a diagnosis from doctors, but depression was not subdivided into bipolar disorder or persistent depressive disorder, which are often confused in the general population. In addition, there were also limitations in the absence of evaluation of anorexia nervosa, binge eating associated with bulimia nervosa, elimination behavior, and body dysmorphic disorders, which may be associated with suicide. The effects of obesity on mental health will be elucidated in further detail if a prospective study is conducted as a follow-up study with the discussion of such areas, in addition to other mental health medical symptoms such as anxiety and obsession.

\section{CONCLUSION}

Suicide planning rate was higher in the low-educated, unemployed, low-income group, and participants suffering from stroke, heart disease, depression, and cir- rhosis. Suicide attempt rate was higher in the female, unemployed, and participants suffering from stroke, and depression. The higher the PHQ-9 score, the higher both suicide plans and suicide attempts were. Interestingly, in the case of participants with diabetes, the suicide attempt rate was significantly lower.

In this study, there was no difference in suicide plans between individuals with and without obesity in the adult population aged over 19 years in South Korea; however, the probability of having a suicide attempt was significantly higher. Follow-up studies to complement the limitations of this study will help in developing an integrated approach for treating physical and mental health conditions to prevent suicide by considering the effects of obesity.

\section{CONFLICTS OF INTEREST}

The authors have nothing to disclose.

\section{ORCID}

\author{
Jung Hyuck Park \\ https://orcid.org/0000-0001-8575-284X \\ Mi Kyoung Seo \\ https://orcid.org/0000-0002-3368-4950 \\ Taekjoong Kim \\ https://orcid.org/0000-0002-3926-3735 \\ Sung Woo Park \\ https://orcid.org/0000-0001-8601-9084 \\ Jung Goo Lee \\ https://orcid.org/0000-0003-3393-2667
}

\section{REFERENCES}

1. Seo MH, Lee WY, Kim SS, Kang JH, Kang JH, Kim KK, et al. 2018 Korean Society for the Study of Obesity guideline for the management of obesity in Korea. J Obes Metab Syndr 2019;28:40-5.

2. Global Burden of Disease Study 2015 (GBD 2015) obesity and overweight prevalence 1980-2015. Seattle: Institute for Health Metrics and Evaluation (IHME); 2017.

3. Seo MH, Kim YH, Han K, Jung JH, Park YG, Lee SS, et al. Prevalence of obesity and incidence of obesity-related comorbidities in Koreans Based on National Health Insurance Service Health Checkup data 2006-2015. J Obes Metab Syndr 2018;27:46-52. 
4. Wilborn C, Beckham J, Campbell B, Harvey T, Galbreath M, La Bounty P, et al. Obesity: prevalence, theories, medical consequences, management, and research directions. J Int Soc Sports Nutr 2005;2:4-31.

5. Kivimäki M, Batty GD, Singh-Manoux A, Nabi H, Sabia S, Tabak AG, et al. Association between common mental disorder and obesity over the adult life course. Br J Psychiatry 2009;195:149-55.

6. Mann JJ. Neurobiology of suicidal behaviour. Nat Rev Neurosci 2003;4:819-28.

7. Mościcki EK. Epidemiology of suicidal behavior. Suicide Life Threat Behav 1995;25:22-35.

8. Brown GK, Beck AT, Steer RA, Grisham JR. Risk factors for suicide in psychiatric outpatients: a 20-year prospective study. J Consult Clin Psychol 2000;68:371-7.

9. Hoven CW, Mandell DJ, Bertolote JM. Prevention of mental ill-health and suicide: public health perspectives. Eur Psychiatry 2010;25:252-6.

10. Zhang J. Epidemiological link between low cholesterol and suicidality: a puzzle never finished. Nutr Neurosci 2011;14:268-87.

11. Dong C, Li WD, Li D, Price RA. Extreme obesity is associated with attempted suicides: results from a family study. Int J Obes (Lond) 2006;30:388-90.

12. Carpenter KM, Hasin DS, Allison DB, Faith MS. Relationships between obesity and DSM-IV major depressive disorder, suicide ideation, and suicide attempts: results from a general population study. Am J Public Health 2000;90:2517.

13. van Wijnen LG, Boluijt PR, Hoeven-Mulder HB, Bemelmans WJ, Wendel-Vos GC. Weight status, psychological health, suicidal thoughts, and suicide attempts in Dutch adolescents: results from the 2003 E-MOVO project. Obesity (Silver Spring) 2010;18:1059-61.

14. Mather AA, Cox BJ, Enns MW, Sareen J. Associations of obesity with psychiatric disorders and suicidal behaviors in a nationally representative sample. J Psychosom Res 2009;66:277-85.

15. Bjerkeset O, Romundstad P, Evans J, Gunnell D. Association of adult body mass index and height with anxiety, depression, and suicide in the general population: the HUNT study. Am J Epidemiol 2008;167:193-202.

16. Kaplan MS, McFarland BH, Huguet N. The relationship of body weight to suicide risk among men and women: results from the US National Health Interview Survey Linked Mortality File. J Nerv Ment Dis 2007;195:948-51.

17. Mukamal KJ, Kawachi I, Miller M, Rimm EB. Body mass index and risk of suicide among men. Arch Intern Med 2007;167:468-75.

18. Kim T, Kim JJ, Kim MY, Kim SK, Roh S, Seo JS. A Ushaped association between body mass index and psychological distress on the multiphasic personality inventory: retrospective cross-sectional analysis of 19-year-old men in Korea. J Korean Med Sci 2015;30:793-801.

19. Herhaus B, Kersting A, Brähler E, Petrowski K. Depression, anxiety and health status across different BMI classes: a representative study in Germany. J Affect Disord 2020;276:45-52.

20. Kim H, Jeon HJ, Bae JN, Cho MJ, Cho SJ, Lee H, et al. Association of Body Mass Index with suicide behaviors, perceived stress, and life dissatisfaction in the Korean general population. Psychiatry Investig 2018;15:272-8.

21. Kim DK, Song HJ, Lee EK, Kwon JW. Effect of sex and age on the association between suicidal behaviour and obesity in Korean adults: a cross-sectional nationwide study. BMJ Open 2016;6:e10183.

22. Lee SA, Jang SY, Shin J, Ju YJ, Nam JY, Park EC. The association between inappropriate weight control behaviors and suicide ideation and attempt among Korean adolescents. J Korean Med Sci 2016;31:1529-37. 